\title{
Effects of Semi-Solid Enteral Formula on Aspiration Pneumonia and Diarrhea
}

\author{
Minoru Oishi*, Minako Yasuda, Mao Chikamatsu, Rena Akiyama, Michio Yamamoto, \\ Keisuke Terakawa, Yumi Suzuki, Mizuki Ando, Mariko Shimada, Tadashi Kumagai, \\ Akiko Nakayama
}

Swallowing Team, Koshinkai Izu Tobu Hospital, Higashi-Izu, Japan

Email:*dr333@icloud.com

How to cite this paper: Oishi, M., Yasuda, M., Chikamatsu, M., Akiyama, R., Yamamoto, M., Terakawa, K., Suzuki, Y., Ando, M., Shimada, M., Kumagai, T. and Nakayama, A. (2020) Effects of Semi-Solid Enteral Formula on Aspiration Pneumonia and Diarrhea. International Journal of Clinical Medicine, 11, 193-198.

https://doi.org/10.4236/ijcm.2020.114019

Received: March 23, 2020

Accepted: April 17, 2020

Published: April 20, 2020

Copyright $\odot 2020$ by author(s) and Scientific Research Publishing Inc. This work is licensed under the Creative Commons Attribution International License (CC BY 4.0).

http://creativecommons.org/licenses/by/4.0/

\begin{abstract}
Objective: The effects of semi-solid enteral formula were investigated in tube feeding patients with aspiration pneumonia and/or diarrhea caused by liquid enteral formula. Methods: In 25 cases of aspiration pneumonia and 10 cases of diarrhea ( 5 cases had both aspiration pneumonia and diarrhea) caused by liquid enteral formula, the rate of improvement by changing the liquid enteral formula to semi-solid enteral formula was studied. The semi-solid enteral formula (PG Soft $\left.{ }^{\oplus} \mathrm{EJ}\right)$ was infused via the nasogastric tube (16Fr) or percutaneous endoscopic gastrostomy (PEG) tube (20Fr). Results: The semi-solid enteral formula was effective in $72 \%$ of aspiration pneumonia cases and in $80 \%$ of diarrhea cases. Constipation was observed in one case but was controlled with magnesium oxide. Conclusion: In cases of aspiration pneumonia and/or diarrhea, changing liquid enteral formula to semi-solid enteral formula frequently shows improvement.
\end{abstract}

\section{Keywords}

Semi-Solid Enteral Formula, Tube Feeding, Aspiration Pneumonia, Diarrhea, Liquid Formula Syndrome

\section{Introduction}

Gastroenteric tube feeding plays a major role in the management of patients with poor voluntary intake, chronic neurological or mechanical dysphagia or gut dysfunction, and patients who are critically ill [1]. But tube feeding is a risk indicator of aspiration pneumonia [2] and diarrhea is a common and problematic complication of enteral nutrition [3].

In order to reduce the incidence of aspiration pneumonia and/or diarrhea in 
tube feeding, modification of the volume and administration method of tube feeding [4], measurement of gastric residual volumes at monitoring intervals of 4 hours [5], placement of feeding tubes postpylorically [6] and use of feeding pump with a continuous infusion for 20 hours adjusting infusion rate based on gastric residual volume [7] have been considered.

Semi-solid enteral formula has been demonstrated to reduce the incidence of aspiration pneumonia but is difficult to administer via the nasogastric tube [8]. We investigated the effects of changing liquid enteral formula to semi-solid enteral formula in patients with aspiration pneumonia and/or diarrhea in whom liquid enteral formula had been infused via the nasogastric tube or PEG tube.

\section{Materials and Methods}

Patients with liquid enteral formula who showed aspiration pneumonia and/or diarrhea in our hospital were asked to participate in our study. Thirty-one patients agreed to participate but one patient withdrew from our study because symptoms of reflux esophagitis were aggravated not by semi-solid enteral formula but by $16 \mathrm{Fr}$ nasogastric tube. All patients were on total enteral nutrition.

The mean age of the 30 patients was 79.5 years (youngest 49 , oldest 97 years), female:male ratio was $21: 9$ and the mean body weight was $47.4 \mathrm{~kg}$. Twenty-five patients showed aspiration pneumonia and 10 patients showed diarrhea (five patients showed both aspiration pneumonia and diarrhea). The enteral formula was infused via the nasogastric tube in 26 patients and via the PEG tube in four patients. The underlining diseases were cerebral infarction, cerebral hemorrhage, subarachnoid hemorrhage, Alzheimer's disease, Parkinson's disease, amyotrophic lateral sclerosis, lung cancer, liver cancer, malignant lymphoma, etc.

This study was approved by the ethics committee of our hospital and we got the informed consent from the patients and/or their family. We changed the liquid enteral formula to semi-solid enteral formula (PG Soft $\left.{ }^{\oplus} \mathrm{EJ}\right)$ and infused via the nasogastric tube (16Fr) or PEG tube (20Fr). We infused $300-400 \mathrm{kcal}$ of PG $\mathrm{Soft}^{\oplus} \mathrm{EJ}$ for 30 minutes using a pressurized bag (Figure 1) three times a day. One hundred $\mathrm{mL}$ of water was injected 30 minutes before the infusion of PG Soft ${ }^{\oplus} \mathrm{EJ}$ and $50 \mathrm{~mL}$ of water was injected after the infusion of PG Soft ${ }^{\oplus} \mathrm{EJ}$ via the nasogastric tube or PEG tube. The liquid enteral formula was Isocal ${ }^{\oplus}$ Bag $2 \mathrm{~K}$ in 25 cases, Peptamen ${ }^{\odot}$ in 3 cases, Isocal ${ }^{\odot}$ Support Bag in 1 case and Renalen ${ }^{\circledR} \mathrm{D}$ in 1 case.

Diarrhea was defined as having loose or watery stools at least three times per day, or more frequently than normal for an individual [9]. The effects of PG Soft ${ }^{\circledR}$ EJ were classified into improvement, worsening, and no effects.

\section{Results}

Table 1 shows the effects of changing liquid enteral formula to PG Soft ${ }^{\oplus}$ EJ. Eighteen out of the 25 cases of aspiration pneumonia and 8 out of the 10 cases of diarrhea showed improvement. None of the 30 cases showed worsening. A case 


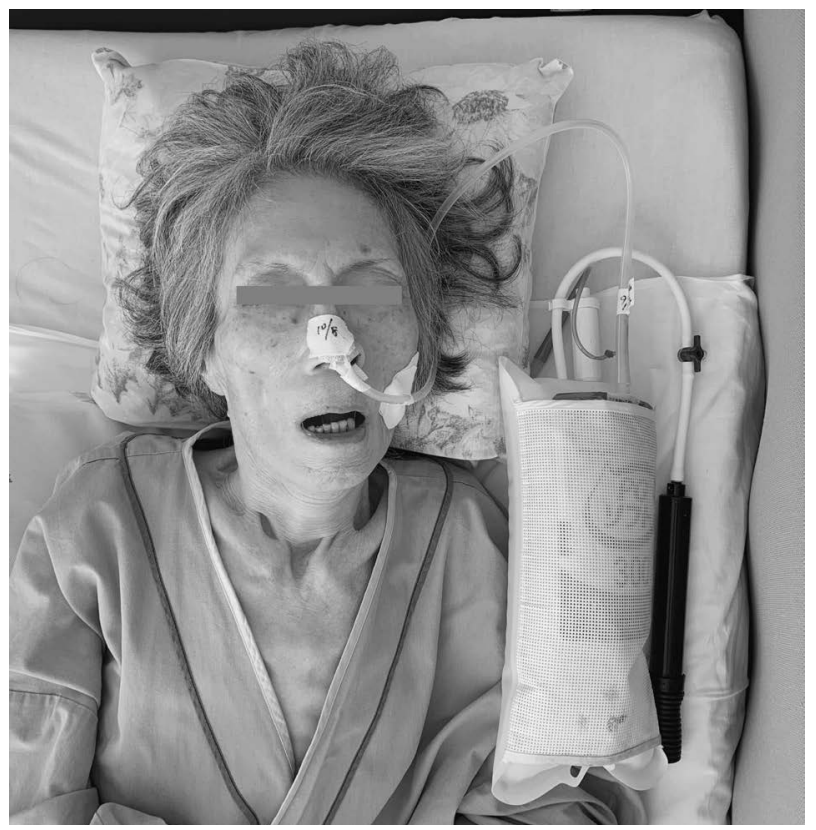

Figure 1. Method of administration of PG Soft ${ }^{\circledR}$ EJ. The semi-solid enteral formula was infused with a pressurized bag which may be placed on the bed.

Table 1. The effects of changing liquid enteral formula to PG Soft ${ }^{\circledast} \mathrm{EJ}$.

\begin{tabular}{cccc}
\hline & Improvement & Worsening & No Effects \\
\hline Aspiration Pneumonia & $72 \%$ & $0 \%$ & $28 \%$ \\
Diarrhea & $80 \%$ & $0 \%$ & $20 \%$ \\
\hline
\end{tabular}

of aspiration pneumonia developed constipation which was controlled with magnesium oxide. Besides that, no adverse effects were noted.

\section{Discussion}

Liquid formula syndrome is various complications of liquid enteral formula which are due to low viscosity [10]. Some clinical complications that can occur with enteral nutrition, such as diarrhea and gastroesophageal reflux, are observed after administration of a liquid enteral formula and thickened enteral formula has been reported to be able to prevent these complications [11]. Thickened enteral formula is also referred to as semi-solid enteral formula [12]. Aspiration pneumonia is presumably due to severe gastroesophageal reflux and semi-solid enteral formula has been demonstrated to reduce the incidence of aspiration pneumonia [8].

The positive effects of thickened enteral formula are considered to be based on its high viscosity, which reduces the outflow rate of gastric contents and thereby helps to prevent diarrhea and gastroesophageal reflux [12]. Thickened enteral formula is a formula in which viscosity is intentionally increased to prevent enteral nutrition-related complications, such as aspiration pneumonia and diarrhea 
[12] and has been used mainly in Japan [11]. It has been more than a decade since semi-solid enteral formula was developed but there is limited published literature on this topic despite the wide usage of semi-solid enteral formula in Japan [13]. Semi-solid enteral formula is considered to be more physiologic because swallowed food does not enter the stomach in the liquid form [13].

Semi-solid enteral nutrients have high viscosity and, therefore, are typically administered through a large-diameter tube [11] [14]. We used 12Fr nasogastric tube and 20Fr PEG tube for liquid enteral formula and 16Fr nasogastric tube and 20Fr PEG tube for PG Soft ${ }^{\oplus}$ EJ. One patient withdrew from the study because symptoms of reflux esophagitis were aggravated not by semi-solid enteral formula but by $16 \mathrm{Fr}$ nasogastric tube. We could infuse PG Soft ${ }^{\oplus} \mathrm{EJ}$ for 30 minutes with the use of a pressurized bag.

Table 2 shows the difference between Isocal ${ }^{\oplus}$ Bag $2 \mathrm{~K}$ (400 kcal) and PG Soft ${ }^{\circledR}$ EJ (400 kcal). The viscosity is the biggest difference between the two [13]. Several studies examining thickened enteral formula with viscosity ranging from 900 to $20,000 \mathrm{mPa} \cdot \mathrm{s}$ have shown the efficacy of thickened enteral formula in preventing gastroesophageal reflux in this range [12]. Several clinical case studies have been published on prevention of diarrhea using thickened enteral formula with viscosity ranging from 3000 to $20,000 \mathrm{mPa} \cdot \mathrm{s}$ [12]. The viscosity of Isocal ${ }^{\circledR} \mathrm{Bag}^{2 \mathrm{~K}}$ is $20,000 \mathrm{mPa} \cdot \mathrm{s}$ and this viscosity is considered to be effective for prevention of both aspiration pneumonia and diarrhea. We used PG Soft ${ }^{\oplus}$ EJ because of its high viscosity but the other semi-solid enteral formulas with viscosity ranging from 3000 to $20,000 \mathrm{mPa} \cdot \mathrm{s}$ [12] are considered to be also effective.

In the case of liquid enteral formula we administered $150 \mathrm{~mL}$ of water simultaneously with the liquid enteral formula and $50 \mathrm{~mL}$ of water was injected after the infusion of liquid enteral formula to flush the nasogastric tube or PEG tube. But in the case of semi-solid enteral formula, simultaneous administration of water decreases its viscosity. So, we injected $100 \mathrm{~mL}$ of water 30 minutes before and $50 \mathrm{~mL}$ of water after the infusion of PG Soft ${ }^{\circledast}$ EJ via the nasogastric tube or PEG tube.

Table 2. Comparison between Isocal ${ }^{\oplus}$ Bag $2 \mathrm{~K}$ and PG Soft ${ }^{\circledast} \mathrm{EJ}$.

\begin{tabular}{ccc}
\hline & Isocal $^{\oplus}$ Bag $2 \mathrm{~K}$ & PG Soft $^{\circledR} \mathrm{EJ}$ \\
\hline Energy (kcal) & 400 & 400 \\
Volume or Weight & $200 \mathrm{~mL}$ & $267 \mathrm{~g}$ \\
Water & $140 \mathrm{~mL}$ & $175 \mathrm{~g}$ \\
Protein (g) & 14.4 & 16.0 \\
Fat (g) & 16.0 & 8.8 \\
Saccharides (g) & 47.6 & 62.7 \\
Dietary Fiber (g) & 4.0 & 1.5 \\
Viscosity (mPa.s) & 40 & 20,000
\end{tabular}




\section{Acknowledgements}

We got an approval to use the photograph from the patient and her family.

\section{Conflicts of Interest}

The authors declare no conflicts of interest regarding the publication of this paper.

\section{References}

[1] Blumenstein, I., Shastri, Y.M. and Stein, J. (2014) Gastroentric Tube Feeding: Techniques, Problems and Solutions. World Journal of Gastroenterology, 20, 8505-8524. https://doi.org/10.3748/wjg.v20.i26.8505

[2] Hollaar, V., van der Maarel-Wierink, C., van der Putten, G.-J., van der Sanden, W., de Swart, B., et al. (2016) Defining Characteristics and Risk Indicators for Diagnosing Nursing Home-Acquired Pneumonia and Aspiration Pneumonia in Nursing Home Residents, Using the Electronically-Modified Delphi Method. BMC Geriatrics, 16, 60-70. https://doi.org/10.1186/s12877-016-0231-4

[3] Whelan, K. and Schneider, S.M. (2011) Mechanisms, Prevention, and Management of Diarrhea in Enteral Nutrition. Current Opinion in Gastroenterology, 27, 152-159. https://doi.org/10.1097/MOG.0b013e32834353cb

[4] Hirakawa, P. (2020) A Case in Which Aspiration Improved by Modification of Volume and Administration Method of Tube Feeding. Kango Jissenno Kagaku, 45: 86-89. (In Japanese)

[5] Büyükçoban, S., Akan, M., Koca, U., Eğlen, M.Y., Çiçeklioğlu, M., et al. (2016) Comparison of Two Different Enteral Nutrition Protocol in Critically Ill Patients. Turkish Journal of Anaesthesiology \& Reanimation, 44, 265-269. https://doi.org/10.5152/TJAR.2016.92499

[6] Metheny, N.A., Stewart, B.J. and McClave, S.A. (2011) Relationship between Feeding Tube Site and Respiratory Outcomes. Journal of Parenteral and Enteral Nutrition, 35, 346-355. https://doi.org/10.1177/0148607110377096

[7] Chen, S., Xian, W., Cheng, S., Zhou, C., Zhou, H., et al. (2015) Risk of Regurgitation and Aspiration in Patients Infused with Different Volumes of Enteral Nutrition. Asia Pacific Journal of Clinical Nutrition, 24, 212-218.

[8] Toh Yoon, E.W. (2018) A Novel Semi-Solidifying Liquid Formula via the Nasogastric Route to Maintain Enteral Nutrition in the Event of Recurrent Aspiration Pneumonia: A Case Report. Clinical Case Reports, 6, 1708-1712. https://doi.org/10.1002/ccr3.1668

[9] UNICEF, WHO (2009) Diarrhea: Why Children are Still Dying and What Can Be Done. World Health Organization, Geneva, 9.

[10] Shirotani, N. and Goda F. (2011) Liquid Formula Syndrome and Progress of Semi-Solid Formula. Gekkan Nursing, 31, 149-152. (In Japanese)

[11] Wakita, M., Masui, H., Ichimaru, S. and Amagai, T. (2012) Determinant Factors of the Viscosity of Enteral Formulas: Basic Analysis of Thickened Enteral Formulas. Nutrition in Clinical Practice, 27, 82-90. https://doi.org/10.1177/0884533611427146

[12] Ichimaru, S. and Amagai, T. (2014) Viscosity Thickened Enteral Formula. Diet and Nutrition in Critical Care, Springer, New York, 1-15. https://doi.org/10.1007/978-1-4614-8503-2_27-1

[13] Toh Yoon, E.W., Yoneda, K. and Nishihara, K. (2016) Semi-Solid Feeds May Re- 
duce the Risk of Aspiration Pneumonia and Shorten Postoperative Length of Stay after Percutaneous Endoscopic Gastrostomy (PEG). Endoscopy International Open, 4, E1247-E1251. https://doi.org/10.1055/s-0042-117218

[14] Akashi, T., Matsumoto, K. and Hashimoto, R. (2017) Continuation of Enteral Nutrition and Relief from Vomiting by Administration of a New Formula: a Case Report. Clinical Nutrition Research, 6, 306-309.

https://doi.org/10.7762/cnr.2017.6.4.306 